\title{
Patient preferences in the treatment of hemophilia A: impact of storage conditions on product choice
}

This article was published in the following Dove Press journal:

Patient Preference and Adherence

\author{
Bernd Tischer' \\ Renato Marino ${ }^{2}$ \\ Mariasanta Napolitano 3 \\ 'Kantar Health, Munich, Germany; \\ ${ }^{2} \mathrm{Haemophilia}$ and Thrombosis \\ Centre, University Hospital of \\ Bari, Apulia, Italy; ${ }^{3}$ University of \\ Palermo, Reference Regional Center \\ for Thrombosis and Hemostasis \\ Hematology Unit, Palermo, Italy
}

\begin{abstract}
Objectives: To gain insights into the usage of factor VIII (FVIII) products by patients diagnosed with moderate/severe hemophilia A, and to assess the impact and perceived importance of product storage.
\end{abstract}

Methods: In this study, 200 patients diagnosed with moderate or severe hemophilia A across seven countries participated. Data were collected via a 30-minute, face-to-face interview in six countries and via a web-based survey in the seventh country. The questionnaire evaluated the effect of six features associated with FVIII products on the choice of the product; the structure and flow of data collection was designed to eliminate potential bias.

Results: Two-thirds of the respondents were using recombinant FVIII products. Only 17\% were generally dissatisfied with current FVIII products, whereas $>40 \%$ of the respondents were dissatisfied with frequency of administration and storage issues when traveling. The majority noted restrictions in their daily activities, particularly travel and sports. Most of them $(85 \%)$, stored their product in the refrigerator and of these, $88 \%$ believed that it should always be stored there. These patients were also less satisfied with the product overall, more concerned about storage temperature, more restricted in daily activities, and spent more time on preparation and injection compared with patients who stored their product at room temperature. Conjoint analysis revealed that origin of FVIII (plasma-derived vs recombinant) was the strongest driver of product choice among all respondents, followed by storage flexibility (temperature), reconstitution device, and administration frequency. In this study, we did not investigate the efficacy and safety of the product.

Conclusion: Not refrigerating FVIII products was associated with greater patient satisfaction and less restriction on daily activities. If efficacy and safety are unaffected, then storing FVIII at room temperature might have a positive impact on product choice. Few patients were aware that FVIII can be stored without refrigeration, suggesting that health care professionals who treat hemophilia should communicate this aspect to the patient (depending on the labeled option); this approach might offer patients greater flexibility when traveling and require less time for reconstitution.

Keywords: hemophilia A, recombinant FVIII, plasma-derived FVIII, storage, reconstitution, stability

\section{Plain language summary}

This study was performed to help understand how real-life use and ease of storage affect the choice of treatment product (factor VIII) for patients with hemophilia A. Feedback was collected from 200 patients across seven countries using face-to-face interviews and a web-based survey. Only $17 \%$ of the patients were found to be dissatisfied overall with their treatment product, whereas over $40 \%$ of the patients were found to be dissatisfied with how often their treatment product needed to be taken and with ease of storage when traveling. Many patients thought that using their treatment product interfered with daily activities, including travel
Correspondence: Mariasanta Napolitano University of Palermo, Reference Regional Center for Thrombosis and Hemostasis Hematology Unit, 90127 Palermo, Italy

Tel +390916554405

Fax +3909| 6554402

Email marysanta@libero.it
Patient Preference and Adherence 20|8:12 43|-44|

431 
and sports. The treatment product origin (recombinant or plasmaderived factor VIII) was considered most important for the choice of the treatment, followed by ease of storage, ease of handling, and how often the treatment needed to be taken. Patients preferred not having to refrigerate FVIII products and those that did were less satisfied with the product overall. Many patients were not aware that FVIII products can be stored at room temperature. This needs to be better communicated to patients by health care professionals treating hemophilia.

\section{Introduction}

Hemophilia $\mathrm{A}$ is an $\mathrm{X}$-linked recessive inherited bleeding disorder characterized by the deficiency of clotting factor VIII (FVIII). In the severe form of hemophilia, there is a high risk of spontaneous bleeding in joints, muscles, or soft tissues. ${ }^{1}$ Patients with severe hemophilia A are known to benefit from prophylactic treatment, ${ }^{2}$ and most patients administer intravenous FVIII twice or thrice a week to prevent spontaneous bleeding. The remainder of the patients treat on-demand, which means that they administer FVIII only to stop bleeding. ${ }^{3,4}$ Benefits of adherence to prophylaxis among patients with severe hemophilia have been well demonstrated. ${ }^{3}$ However, treatment practice varies greatly between countries, and access to hemophilia care is still not uniform worldwide. ${ }^{5,6}$

FVIII is administered by an intravenous injection, usually by the patient or by their caregivers. Prior to the injection, the FVIII concentrate, which is a lyophilized powder, must be reconstituted by mixing it with a diluent in multiple steps. Manufacturers recommend storing FVIII in a refrigerator and reconstituting the product at room temperature. However, most FVIII products can be stored at room temperature, with a limited shelf-life ranging from 3 to 12 months depending on the brand.

A review of the available literature regarding clinical trials evaluating the efficacy of FVIII and factor IX products or bypassing agents demonstrated an overall improvement in health-related quality of life with prophylactic treatment in hemophilia. ${ }^{7}$ However, the inconvenience of reconstituting and administering FVIII injections may have a negative impact on the daily life of the patient, thus creating a barrier to patient adherence to medication. ${ }^{8,9}$ Furthermore, storing the FVIII concentrate in the refrigerator is an additional inconvenience. Although most FVIII products remain stable at room temperature up to $25^{\circ} \mathrm{C}$ for a limited time, patients may worry about its stability when traveling and interrupting the cool chain. Carrying all items required for reconstitution and limited space in the refrigerator create additional inconveniences on trips. As patients with hemophilia have become more mobile, in line with our increasingly mobile society, ${ }^{10}$ it is reasonable to assume that the flexibility of storing FVIII concentrates without refrigeration might be an important patient requirement to be addressed. ${ }^{11}$

A recent study in a different therapeutic area, growth hormone therapy, showed that patients prefer a storage-flexible product when they have the choice, and that growth hormone products that are stable at room temperature are associated with shorter injection times, greater patient adherence to medication, less wastage, and fewer restrictions of daily activities due to difficulties with injections. ${ }^{12}$ Recent studies on patients with hemophilia A investigated frequency of administration, type of reconstitution device, out-of-pocket costs, treatment side effects, efficacy (annual bleeding rate), diluent volume, number of vials per infusion, and experience of manufacturer as criteria for patients' preference. ${ }^{8,13-15}$ It can be summarized from these studies that efficacy (annual bleeding rate in prophylactic treatment) and frequency of administration (2-3×/week vs $1 \times /$ week vs $1 \times / 2$ weeks) had a high impact on patients' treatment preference. However, the aforementioned studies evaluating patient preferences in hemophilia A have not investigated the importance of storage flexibility (ie, the possibility of storage with or without refrigeration) to the same extent as other product features.

Thus, the following were the aims of this study: first, to provide reliable patient insights on real-life use of FVIII products and to find the association between FVIII storage conditions, daily life activities, satisfaction with treatment, and unmet needs. Second, to investigate the relative importance of storage flexibility compared with other product features.

\section{Methods}

This study was conducted in seven countries in three regions - Europe (France, Italy, and UK), Latin America (Argentina, Brazil, and Mexico), and Japan - through a structured questionnaire that took $\sim 30$ min to complete. Individual interviews were conducted face-to-face using computerassisted personal interviewing in all countries except Japan, where data were collected via a web-based survey.

The questionnaire comprised five sections: current use of FVIII products, satisfaction with current treatment, unmet needs, product preference, and demographics. In all but the product preference section, patients were tasked with responding to a mixture of simple closed questions, rating scales, and open-ended questions.

The product preference section was more complex and designed to investigate the importance of individual product attributes in relation to product choice. Conjoint analysis, a 
well-established method that provides in-depth understanding of which product attributes are valued most highly by respondents and which are most likely to drive product choice was chosen for this study.

Patients were presented with scenarios showing hypothetical product profiles covering six attributes (origin of FVIII, storage flexibility [temperature], storage flexibility [shelf life], reconstitution device, stability out of refrigerator after mixing, and frequency of administration in prophylaxis) for three different FVIII products. Patients were asked to indicate which of the three products they preferred. Based on the observed likelihood of choosing a product with a given attribute level, for each attribute and level, its value (utility score) was calculated. Table 1 shows the six product attributes and their levels used in defining FVIII products.

In all, 16 randomized scenarios were presented to each patient. Table 2 shows one of these randomly generated scenarios describing three products in one of the choice tasks. Patients were told to assume that all three products were identical to each other and to their current FVIII product in terms of efficacy and safety.

Based on the product selected in each scenario, the contribution of each attribute to product choice was measured. For each attribute, the contribution was the part-worth associated to the level describing the products in the conjoint scenarios.
Part-worth utilities measure how valuable each attribute level is (eg, $2 \times /$ week administration) relative to the other levels (eg, $3 \times /$ week administration). The primary outcome of conjoint analysis is the estimation of the part-worth utilities associated to each level of each attribute describing the products in the conjoint design.

Four pilot interviews were conducted in London, UK, in an interviewing facility to verify that all questions were easily understood. Thereafter, all remaining face-to-face interviews in Europe and Latin America were conducted at a location chosen by the individual patient (average interview duration: $30 \mathrm{~min}$ ).

Before initiating recruitment and interviewing patients, the design and the methodology were submitted to the institutional review board (IRB) of the Freiburger EthikKommission. After reviewing the study protocol, the IRB granted approval on May 9, 2016.

\section{Statistical analysis}

Descriptive statistics were used to summarize responses to the individual questions. Subgroup comparisons (eg, differences between patient subgroups) were analyzed with a chi-square test for nominal data or two-independent samples $t$-tests to compare means of a normally distributed, interval-dependent variable for two independent groups.

Table I Product characteristics (attributes) and levels to create hypothetical FVIII product profiles

\begin{tabular}{|c|c|}
\hline Attributes & Levels \\
\hline \multirow[t]{2}{*}{ Origin of FVIII } & (I) FVIII made from human blood plasma \\
\hline & (2) Plasma-free/recombinant (FVIII made completely in a laboratory with DNA technology) \\
\hline \multirow[t]{4}{*}{ Storage flexibility (temperature) } & $\begin{array}{l}\text { (I) Needs to be stored in the refrigerator at } 2^{\circ} \mathrm{C}-8^{\circ} \mathrm{C}(\sim 10 \mathrm{~min} \text { until it reaches room temperature } \\
\text { before you can inject it) }\end{array}$ \\
\hline & (2) Can be stored anywhere outside the refrigerator at $\leq 25^{\circ} \mathrm{C}$ \\
\hline & (3) Can be stored anywhere outside the refrigerator at $\leq 30^{\circ} \mathrm{C}$ \\
\hline & (4) Can be stored anywhere outside the refrigerator at $\leq 40^{\circ} \mathrm{C}$ \\
\hline Storage flexibility (shelf life): & (I) Can be stored for $\leq 3$ months \\
\hline Maximum storage time at this & (2) Can be stored for $\leq 6$ months \\
\hline \multirow[t]{2}{*}{ temperature out of the refrigerator ${ }^{\mathrm{a}}$} & (3) Can be stored for $\leq 9$ months \\
\hline & (4) Can be stored for $\leq 12$ months \\
\hline \multirow[t]{4}{*}{$\begin{array}{l}\text { Reconstitution device (mixing FVIII } \\
\text { powder with solvent) }\end{array}$} & $\begin{array}{l}\text { (I) Mix FVIII in a prefilled syringe with both powder and solvent enclosed in separate chambers of the } \\
\text { same syringe }\end{array}$ \\
\hline & $\begin{array}{l}\text { (2) Mix FVIII powder with a solvent in a prefilled syringe. The syringe is connected with the vial } \\
\text { containing FVIII }\end{array}$ \\
\hline & (3) Mix FVIII with two connected vials. One vial contains FVIII powder, and the other contains solvent. \\
\hline & Then put the mixed factor into a syringe connected with the vials \\
\hline Stability out of refrigerator after & (I) 2 hours \\
\hline mixing (in case of unexpected & (2) 3 hours \\
\hline interruptions) & (3) 4 hours \\
\hline Frequency of administration in & (I) $2 \times /$ week \\
\hline prophylaxis & (2) $3 \times /$ week \\
\hline
\end{tabular}

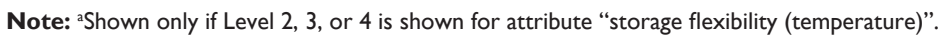

Abbreviations: DNA, deoxyribonucleic acid; FVIII, factor VIII. 
Table 2 Example scenario of the trade-off exercise

\begin{tabular}{|c|c|c|c|}
\hline Example scenario & Product K & Product $\mathbf{L}$ & Product $M$ \\
\hline Origin of FVIII & $\begin{array}{l}\text { Plasma-free/recombinant (FVIII } \\
\text { made completely in a laboratory } \\
\text { with DNA technology) }\end{array}$ & FVIII made from human blood plasma & $\begin{array}{l}\text { Plasma-free/recombinant (FVIII } \\
\text { made completely in a laboratory } \\
\text { with DNA technology) }\end{array}$ \\
\hline Storage flexibility (temperature) & $\begin{array}{l}\text { Can be stored anywhere outside } \\
\text { the refrigerator at } \leq 30^{\circ} \mathrm{C}\end{array}$ & $\begin{array}{l}\text { Can be stored anywhere outside the } \\
\text { refrigerator at } \leq 30^{\circ} \mathrm{C}\end{array}$ & $\begin{array}{l}\text { Needs to be stored in the } \\
\text { refrigerator at } 2^{\circ} \mathrm{C}-8^{\circ} \mathrm{C}(\sim 10 \mathrm{mi} \\
\text { until it reaches room temperatur } \\
\text { before you can inject it })\end{array}$ \\
\hline Storage flexibility (shelf life) & $\leq 12$ months & $\leq 6$ months & \\
\hline $\begin{array}{l}\text { Reconstitution device (mixing } \\
\text { FVIII powder with solvent) }\end{array}$ & $\begin{array}{l}\text { Mix FVIII powder with a solvent } \\
\text { in a prefilled syringe. The syringe } \\
\text { is connected with the vial } \\
\text { containing FVIII }\end{array}$ & $\begin{array}{l}\text { Mix FVIII with two connected vials. } \\
\text { One vial contains FVIII powder, and } \\
\text { the other contains solvent. Then, } \\
\text { take the mixed factor in a syringe } \\
\text { connected with the vials }\end{array}$ & $\begin{array}{l}\text { FVIII in a prefilled syringe } \\
\text { with both powder and solvent } \\
\text { enclosed in separate chambers } \\
\text { of the same syringe }\end{array}$ \\
\hline $\begin{array}{l}\text { Stability outside the refrigerator } \\
\text { after mixing (in case of } \\
\text { unexpected interruptions) }\end{array}$ & 4 hours & 3 hours & 2 hours \\
\hline $\begin{array}{l}\text { Frequency of administration in } \\
\text { prophylaxis }\end{array}$ & $2 \times /$ week & $3 \times /$ week & $3 \times /$ week \\
\hline
\end{tabular}

Notes: Question as framed to responders: "Please imagine that your FVIII product is no longer available. Your doctor presents and recommends three alternative products that are approved for the treatment of hemophilia A. Both efficacy and safety are absolutely identical and comparable with the product you currently use. All three products can be used for prophylaxis (on a regular basis) or on-demand (only occasionally as needed, depending on expected activity level or to treat bleeds)"

Abbreviations: DNA, deoxyribonucleic acid; FVIII, factor VIII.

\section{Sample}

The survey was completed by 200 adult males between June and August 2016 across seven countries: Argentina, Brazil, France, Italy, Mexico, and UK (30 samples in each), and Japan (20 samples).

Eligible patients were between 18 and 75 years of age, diagnosed with moderate or severe hemophilia A by a physician, and currently using a FVIII product.

Patients were recruited locally by health care professionals treating hemophilia A (77 patients), through existing patient contacts available at local health research agencies conducting interviews in hemophilia A (79 patients) and through local patient associations (44 patients). Patients provided written, informed consent before participating in the study. Interviews were conducted either at the patient's home (111 patients), at a central facility such as the office of the local research agency (69 patients), or via the internet (20 patients, in Japan only).

\section{Characteristics of the study population Demographic characteristics}

There was a broad representation of age groups among the patients; $34 \%$ were in the age group of $18-30$ years, $22 \%$ were in the age group of $31-40$ years, and $25 \%$ were in the age group of 41-50 years, and rest of the patients were in the age group of 51-75 years. The average age was 38 years. Over half of the patients (57\%) had attended either secondary school or high school; over one-third of the patients (39\%) had entered university. Most of the patients (68\%) were working with one-third of the total sample involved in "office work".

\section{Clinical characteristics}

Most of the 200 patients (71\%) had a diagnosis of severe hemophilia A. Just over half of the patients (51\%) had received their diagnosis at or shortly after birth, and a further $33 \%$ of the patients received their diagnosis between the ages of 1 and 2 years, resulting in an average age of diagnosis of 1.4 years.

\section{FVIII treatment characteristics}

About one-quarter (26\%) of the patients had been using their current FVIII product for $\geq 11$ years. Overall, the average length of time for current FVIII product use was just $>8$ years. Overall, twice as many patients were being treated with recombinant FVIII products compared with plasma-derived FVIII products (67\% vs 33\%, respectively). In Europe, significantly more patients used recombinant FVIII products (93\%) compared with Latin America $(40 \% ; p<0.001)$; the proportion of patients using recombinant products in Japan was $70 \%$. Prophylactic treatment was more common than on-demand treatment ( $74 \%$ vs $27 \%$, respectively). The frequency of injection differed markedly between the 
two groups; patients using FVIII products prophylactically complied reasonably well with the thrice weekly dosage recommendation, injecting on an average of 2.7 times per week. On-demand users injected much less frequently, just over twice a month on an average.

\section{Travel behavior}

Patients in the study tended to travel reasonably frequently, but mostly for short periods. On an average, they traveled 10.4 times per year, staying away from home for $\geq 1$ night. "A weekend/one or two nights away" occurred on average 6.4 times a year. In contrast, patients were much less likely to travel away from home for longer periods $(2.7 \times /$ year for $>2$ days, $\leq 1$ week at a time; $1.3 \times /$ year for $>1$ week at a time).

\section{Leisure activities}

Seventy-six percent of the patients with hemophilia A were found to be actively engaged in physical activities, of which walking was the most common (46\%). Swimming was also a popular activity (42\%), followed by gymnastics $(18 \%)$ and jogging (14\%). All patients took part in social activities, especially meeting friends and visiting the cinema.

\section{Results}

\section{Usage and administration of current FVIII products}

Patients using prophylactic treatment ( $74 \%$ of the sample) stated that most injections $(88 \%)$ were administered at home. While $19 \%$ of the patients on prophylaxis treatment did not have a specific time of day for the administration of an injection, $26 \%$ of the patients claimed to administer it "when they get up" and 26\% "between breakfast and noon". The remainder of the patients injected "in the evening" or "before going to bed".

Users of prophylactic treatment broadly complied with the most often recommended treatment regimen of three injections per week; over half of the patients (56\%) fully complied, and a small percentage ( $8 \%$ ) injected four times or more per week. However, almost one-third of the patients (29\%) injected only twice per week, giving an overall average of 2.7 injections per week.

A high percentage $(85 \%)$ of patients stored their FVIII product in the refrigerator, whereas the remainder of the patients stored it at room temperature. Just under two-thirds (130 of 200) of the patients stored their FVIII product in their refrigerator alongside groceries, whereas about one-fifth of the patients stored it in a refrigerator dedicated to medicines.
This latter approach was most common in Latin America, where $28 \%$ of the patients used dedicated refrigerators for storage compared with $20 \%$ in Japan and 13\% in Europe.

There were regional and local differences with regard to "storage outside the refrigerator at room temperature" (Table 3). For instance, while $52 \%$ of the patients sampled in the UK stored the product outside the refrigerator, none of the patients surveyed in Latin America or Italy adopted this practice. No statistically significant differences were observed in any other demographic factors between patients who stored their FVIII product inside or outside the refrigerator.

\section{Patients storing FVIII in the refrigerator}

Most of the patients ( $88 \%$ ) who stored FVIII in the refrigerator believed that FVIII products must be stored "in the fridge at all times". Of the remaining $12 \%$ of the patients who did not believe this, the majority $(76 \%)$ believed that the maximum time a FVIII product could be stored outside the refrigerator was around 1-3 months; only 5\% believed that a FVIII product could be stored outside the refrigerator for 7-12 months.

Frequency of travel was closely associated with storage behavior. Patients storing FVIII mainly outside the refrigerator traveled on an average 16 times per year, which is significantly higher than the travel frequency of patients who stored FVIII mainly in the refrigerator ( 9 travels per year; $p<0.01 ; t$-test). Most of the patients who normally stored their FVIII product in the refrigerator at home continued to keep it cool when staying at a hotel $(93 \%)$ or when away from home for leisure activities (76\%). Likewise, $92 \%$ of the patients who stored their FVIII product at room temperature at home continued to do so while traveling.

Storage temperature was a concern for many patients in the subgroup of 169 patients who mainly stored their FVIII product in the refrigerator. Of these patients, $79 \%$ reported worrying at least sometimes ( $\sim 17$ times per year) about the

Table 3 Countries and regions of origin for patients storing their FVIII product in or outside the refrigerator

\begin{tabular}{lll}
\hline $\begin{array}{l}\text { Countryl } \\
\text { region }\end{array}$ & $\begin{array}{l}\text { Storing FVIII in the } \\
\text { refrigerator }(\mathbf{n}=\mathbf{1 6 9})\end{array}$ & $\begin{array}{l}\text { Storing FVIII outside } \\
\text { refrigerator }(\mathbf{n}=\mathbf{3} \mathbf{1})\end{array}$ \\
\hline France & $13 \%$ & $26 \%$ \\
Italy & $18 \%$ & $0 \%$ \\
UK & $8 \%$ & $52 \%$ \\
Argentina & $18 \%$ & $0 \%$ \\
Brazil & $18 \%$ & $0 \%$ \\
Mexico & $18 \%$ & $0 \%$ \\
Japan & $8 \%$ & $23 \%$ \\
Total & $100 \%$ & $100 \%$ \\
\hline
\end{tabular}

Abbreviation: FVIII, factor VIII. 
storage temperature. Notably, patients in Latin America $(n=90)$ worried more often about storage temperatures ( 24 times per year) compared with patients in Europe or Japan ( $~ 9$ times per year; $p<0.001)$.

Nearly two-thirds of the patients $(62 \%)$ felt that an injection of a cold FVIII product was more unpleasant than if it was at room temperature, and $74 \%$ of the patients "wait for their FVIII product to reach room temperature before injecting it", with an average waiting time of $10 \mathrm{~min}$. For these patients, storing FVIII in the refrigerator increased time of preparation. Patients who stored FVIII in the refrigerator reported an average time of $23 \mathrm{~min}$ for the preparation process, which included mixing FVIII with solvent, injection, and cleaning up. By comparison, patients storing FVIII at room temperature prepared their dose in around half the time ( $\sim 12 \mathrm{~min})$.

Although one-third (33\%) of the patients considered the process of storing, preparing, and mixing the FVIII product disruptive to their daily routine, nearly half of them (46\%) said it caused little or no disruption. However, patients who stored their FVIII product outside the refrigerator were much less likely to be affected by the process of storing, preparing, and mixing the product; nearly two-thirds of the patients (61\%) said they experienced little or no disruption compared with $43 \%$ of the patients who refrigerated the product and reported no disruption $(p<0.05)$.

Patients were asked to select from a list of 14 emotional attributes describing how they felt when using their FVIII product in daily life. "Relaxed" was the only attribute showing a significant difference $(p<0.05)$ between patients who stored the product inside or outside the refrigerator $(20 \%$ and $48 \%$, for storage in the refrigerator and storage at room temperature, respectively).

\section{Satisfaction with taking FVIII products}

Patients were asked to indicate their overall level of satisfaction by taking a FVIII product and with several features associated with their current product on a 5-point scale (1 [not at all satisfied] to 5 [extremely satisfied]).

Overall, one-third (32\%) of the patients reported being highly satisfied (very/extremely) with their FVIII product, and $17 \%$ were found to be dissatisfied (Table 4). Highest satisfaction levels were achieved for "efficacy/prevention

Table 4 Satisfaction with FVIII products

\begin{tabular}{|c|c|c|c|c|c|}
\hline \multirow[t]{2}{*}{ Aspect of satisfaction with the FVIII product } & \multicolumn{3}{|c|}{ All patients $(n=200)$} & \multicolumn{2}{|c|}{ \% very/extremely satisfied } \\
\hline & $\begin{array}{l}\text { Very/extremely } \\
\text { satisfied }\end{array}$ & Satisfied & $\begin{array}{l}\text { (Rather) } \\
\text { dissatisfied }\end{array}$ & $\begin{array}{l}\text { Storing FVIII in } \\
\text { the refrigerator } \\
(n=169)\end{array}$ & $\begin{array}{l}\text { Storing FVIII } \\
\text { outside refrigerator } \\
(n=3 I)\end{array}$ \\
\hline Overall satisfaction & $32 \%$ & $52 \%$ & $17 \%$ & $28 \%$ & $52 \% *$ \\
\hline Efficacy/prevention of bleeding & $46 \%$ & $45 \%$ & $10 \%$ & $43 \%$ & $61 \% *$ \\
\hline No skin reaction at the injection site & $41 \%$ & $49 \%$ & $11 \%$ & $40 \%$ & $45 \%$ \\
\hline Storing the FVIII product at home & $30 \%$ & $52 \%$ & $19 \%$ & $29 \%$ & $35 \%$ \\
\hline Procedure of mixing the product before injection & $25 \%$ & $39 \%$ & $36 \%$ & $22 \%$ & $39 \% *$ \\
\hline $\begin{array}{l}\text { Flexibility of storing FVIII outside or in the refrigerator } \\
\text { depending on my personal needs }\end{array}$ & $24 \%$ & $35 \%$ & $42 \%$ & $18 \%$ & $55 \% *$ \\
\hline $\begin{array}{l}\text { Length of time the product can be stored outside the } \\
\text { refrigerator }\end{array}$ & $23 \%$ & $38 \%$ & $40 \%$ & $19 \%$ & $45 \% *$ \\
\hline Size of the vials with FVIII & $22 \%$ & $60 \%$ & $19 \%$ & $18 \%$ & $42 \% *$ \\
\hline $\begin{array}{l}\text { Broad range of available vial doses containing the right } \\
\text { dose for me }\end{array}$ & $22 \%$ & $59 \%$ & $20 \%$ & $20 \%$ & $32 \%$ \\
\hline Storage temperature & $19 \%$ & $52 \%$ & $30 \%$ & $15 \%$ & $39 \% *$ \\
\hline $\begin{array}{l}\text { Length of time the product is stable outside the } \\
\text { refrigerator after mixing }\end{array}$ & $18 \%$ & $50 \%$ & $33 \%$ & $15 \%$ & $35 \% *$ \\
\hline $\begin{array}{l}\text { Time for product to reach room temperature after } \\
\text { taking out of the refrigerator before preparing }\end{array}$ & $18 \%$ & $64 \%$ & $18 \%$ & $18 \%$ & $\mathrm{n} / \mathrm{a}$ \\
\hline Size of the syringe & $17 \%$ & $61 \%$ & $23 \%$ & $15 \%$ & $26 \%$ \\
\hline $\begin{array}{l}\text { Storing the FVIII product with me when I am away } \\
\text { from home }\end{array}$ & $16 \%$ & $44 \%$ & $41 \%$ & $14 \%$ & $29 \% *$ \\
\hline Frequency of administration in prophylaxis & $14 \%$ & $42 \%$ & $45 \%$ & $12 \%$ & $23 \%$ \\
\hline Size of package & $13 \%$ & $48 \%$ & $39 \%$ & $12 \%$ & $16 \%$ \\
\hline $\begin{array}{l}\text { Taking all items needed for FVIII treatment with me } \\
\text { when I am traveling }\end{array}$ & $11 \%$ & $43 \%$ & $47 \%$ & $8 \%$ & $23 \% *$ \\
\hline
\end{tabular}

Notes: ${ }^{*} p<0.05$ (chi-square test). Each aspect of satisfaction was rated on a 5 -point scale: $I=$ not satisfied at all; $2=$ rather unsatisfied; $3=$ satisfied; $4=$ very satisfied; $5=$ extremely satisfied.

Abbreviations: FVIII, factor VIII; n/a, not applicable. 
of bleeding" (46\%), followed by "no skin reaction at the injection site" (41\%). Satisfaction dropped considerably for other features: $30 \%$ were highly satisfied with "storing the FVIII product at home" and 25\% with "procedure of mixing the product before injection".

For several features (ie, "storage temperature", "length of time the product is stable outside the fridge", and "time for product to reach room temperature"), $<20 \%$ of the patients were highly satisfied. "Frequency of administration" and "taking all items needed for FVIII treatment with me when I am traveling" were also concerns for most of the patients.

Overall satisfaction was found to be significantly higher among patients who stored their FVIII product at room temperature compared with those who stored it in the refrigerator (Table 4). Storage had a significant effect on satisfaction levels for specific features of FVIII treatment related to flexibility. For example, significant differences in patient groups were observed for "flexibility of storing FVIII outside or in the fridge depending on my personal needs", "length of time the product can be stored outside the fridge", "storage temperature", "length of time the product is stable outside the fridge after mixing", and "storing the FVIII product with me when I am away from home". In addition, patients storing FVIII outside the refrigerator were more often satisfied with efficacy compared with those who stored it in the refrigerator.

\section{Restrictions on daily life}

Patients were asked to rate their current FVIII product in terms of restriction of activities, using a scale of $1=$ "not restricted at all" and 4="strongly restricted" (Table 5).
Most of the patients (76\%) stated that their participation in sports was restricted to some extent and $23 \%$ found it "strongly restricted" (Table 5). Traveling away from home for $\geq 1$ week was also likely to be restricted, as was traveling in hot countries, short trips, and any airline travel. Morning and evening routines were also affected, although to a lesser extent. In addition, patients who usually stored FVIII product in their refrigerator more frequently reported restrictions compared with those who stored it at room temperature.

\section{Desired improvements to FVIII products/ unmet needs}

An open-ended question invited all patients to describe two improvements to their FVIII product that would make their life with hemophilia easier. The most commonly desired improvements were "reduced frequency of administration" (53\%), "improved mode of administration" (47\%), and "easier storage" (33\%).

"Reduced frequency of administration" was particularly relevant to prophylactic users of FVIII products: $61 \%$ of them had mentioned it, compared with $30 \%$ of on-demand users.

\section{Conjoint analysis: relative impact of attributes on product choice}

Overall, "origin of FVIII" had the highest impact on product choice (Figure 1), followed by "storage flexibility (temperature)" and "reconstitution device". "Frequency of administration in prophylaxis", "storage flexibility (shelf life)", and "stability out of fridge after mixing" had less of an impact on preference. Three aspects of storage flexibility

Table 5 Restriction of activities in daily life by injecting FVIII

\begin{tabular}{|c|c|c|c|c|c|}
\hline \multirow[t]{2}{*}{ Activities } & \multicolumn{3}{|c|}{ All patients $(n=200)$} & \multicolumn{2}{|c|}{$\%$ at least somewhat restricted } \\
\hline & $\begin{array}{l}\text { Not } \\
\text { restricted } \\
\text { at all }\end{array}$ & $\begin{array}{l}\text { (Somewhat) } \\
\text { restricted }\end{array}$ & $\begin{array}{l}\text { Strongly } \\
\text { restricted }\end{array}$ & $\begin{array}{l}\text { Storing FVIII in } \\
\text { the refrigerator } \\
(n=169)\end{array}$ & $\begin{array}{l}\text { Storing FVIII } \\
\text { outside refrigerator } \\
(n=3 I)\end{array}$ \\
\hline Sports activities & $24 \%$ & $54 \%$ & $23 \%$ & $80 \% *$ & $52 \%$ \\
\hline Traveling for I week or longer & $29 \%$ & $66 \%$ & $5 \%$ & $75 \% *$ & $52 \%$ \\
\hline Traveling in countries where it is extremely warm & $36 \%$ & $53 \%$ & $12 \%$ & $66 \%$ & $55 \%$ \\
\hline Traveling by airplane (airport security) & $41 \%$ & $51 \%$ & $9 \%$ & $63 \% *$ & $42 \%$ \\
\hline Leisure activities outside my home & $46 \%$ & $47 \%$ & $7 \%$ & $53 \%$ & $58 \%$ \\
\hline Longer trips in a car or on a train & $48 \%$ & $50 \%$ & $3 \%$ & $56 \% *$ & $32 \%$ \\
\hline Short trips between 2 days and I week & $48 \%$ & $50 \%$ & $3 \%$ & $54 \%$ & $39 \%$ \\
\hline Work trips/business trips & $52 \%$ & $46 \%$ & $2 \%$ & $49 \%$ & $45 \%$ \\
\hline Sleepovers/overnight visits at friends or relatives & $58 \%$ & $40 \%$ & $2 \%$ & $41 \%$ & $45 \%$ \\
\hline Getting ready in the morning & $62 \%$ & $38 \%$ & $1 \%$ & $40 \%$ & $32 \%$ \\
\hline Participating in social activities with other people & $64 \%$ & $35 \%$ & $2 \%$ & $36 \%$ & $39 \%$ \\
\hline My evening routine before I go to bed & $66 \%$ & $34 \%$ & $0 \%$ & $37 \% *$ & $16 \%$ \\
\hline The time I spend with my partner or family members & $76 \%$ & $23 \%$ & $1 \%$ & $25 \%$ & $19 \%$ \\
\hline
\end{tabular}

Notes: $* p<0.05$ (chi-square test). Each aspect of restriction was rated on a 4-point scale: I=not restricted at all; $2=$ somewhat restricted; $3=$ restricted; $4=$ strongly restricted.

Abbreviation: FVIII, factor VIII 


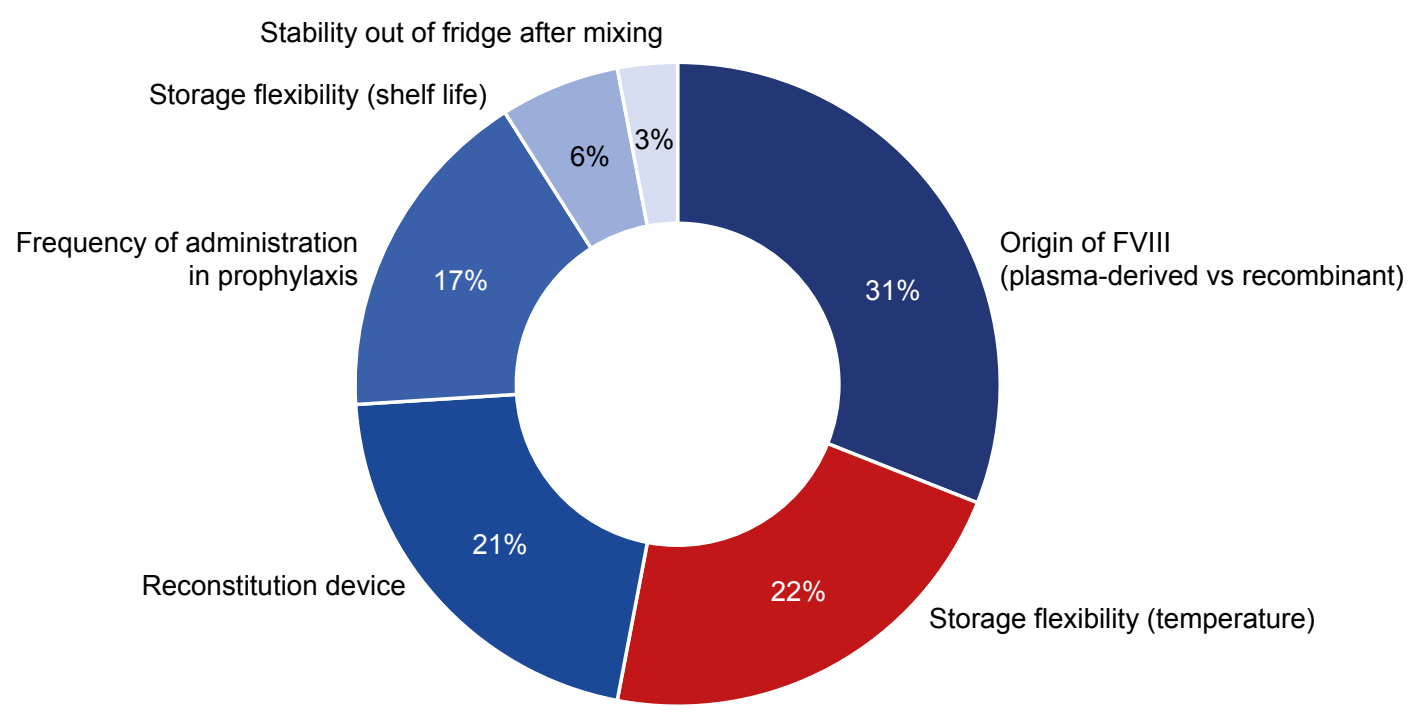

Figure I Relative impact of the attributes on product choice. Abbreviation: FVIII, factor VIII.

(ie, storage temperature, shelf life when FVIII is stored out of fridge, and stability out of fridge after mixing) had different impacts on product choice, with storage temperature $\left(2^{\circ} \mathrm{C}-8^{\circ} \mathrm{C}\right.$ vs $\leq 25^{\circ} \mathrm{C}$ vs $\leq 30^{\circ} \mathrm{C}$ vs $\left.\leq 40^{\circ} \mathrm{C}\right)$ having the greatest effect (Figure 2).

The contribution of individual attributes to product choice depended on the use of FVIII product. For instance, although "frequency of administration in prophylaxis" had an impact of only $17 \%$, the difference between twice or thrice weekly administration in prophylaxis was slightly more important to those patients who currently use FVIII for prophylaxis (19\% impact on preference).

It is important to note that, due to insufficient data, options in dosage frequency excluded once-weekly administration, which presumably would have been more of a driver of choice than either twice or thrice per week. The reason for its exclusion was that, at the time of the study, there were insufficient clinical trial data to demonstrate that once-weekly prophylaxis with FVIII has the same efficacy as administration of twice or thrice per week. ${ }^{16}$

\section{Discussion}

This study investigated the use of FVIII products by patients and assessed the impact of various product features on product choice, specifically the importance of storage flexibility of FVIII products in daily life.

Challenges of prophylactic personalized treatments, ${ }^{17}$ including frequency of infusions needed to maintain factor levels $>1 \%$, patient adherence to medication, physical activity, reliable intravenous access, and quality of life, have been identified in recent years. ${ }^{18}$ Results from this study, particularly those on patient satisfaction and unmet needs, indicate that most patients with hemophilia A are satisfied with efficacy and safety. However, $>40 \%$ of the patients were not satisfied with administration frequency and $\geq 40 \%$ of the patients were dissatisfied with various aspects of storage.

Travel behavior and leisure activities clearly support the conclusion that patients with hemophilia A are part of an active and mobile society, and when away from home they have to carry items needed for reconstitution and administration of the product. This was substantiated by the finding that a considerably high proportion of patients were dissatisfied with several aspects of storing FVIII in a refrigerator.

Most of the patients stored FVIII in the refrigerator at home, and believed that it should always be stored in this way. This finding strongly suggests that patients are unaware that FVIII may be safely stored outside the refrigerator at room temperature (usually up to $25^{\circ} \mathrm{C}$ ) for a limited number of months. The lack of awareness regarding storage temperature was recently demonstrated in another study, where only $13 \%$ of the patients with hemophilia knew the storage temperature. ${ }^{19}$

A subgroup analysis showed several differences between the two groups of patients (storing vs not storing FVIII in the refrigerator). Compared with those patients who stored their FVIII product in the refrigerator, a significantly greater percentage who stored it outside the refrigerator were highly satisfied both overall and when traveling. Furthermore, they 


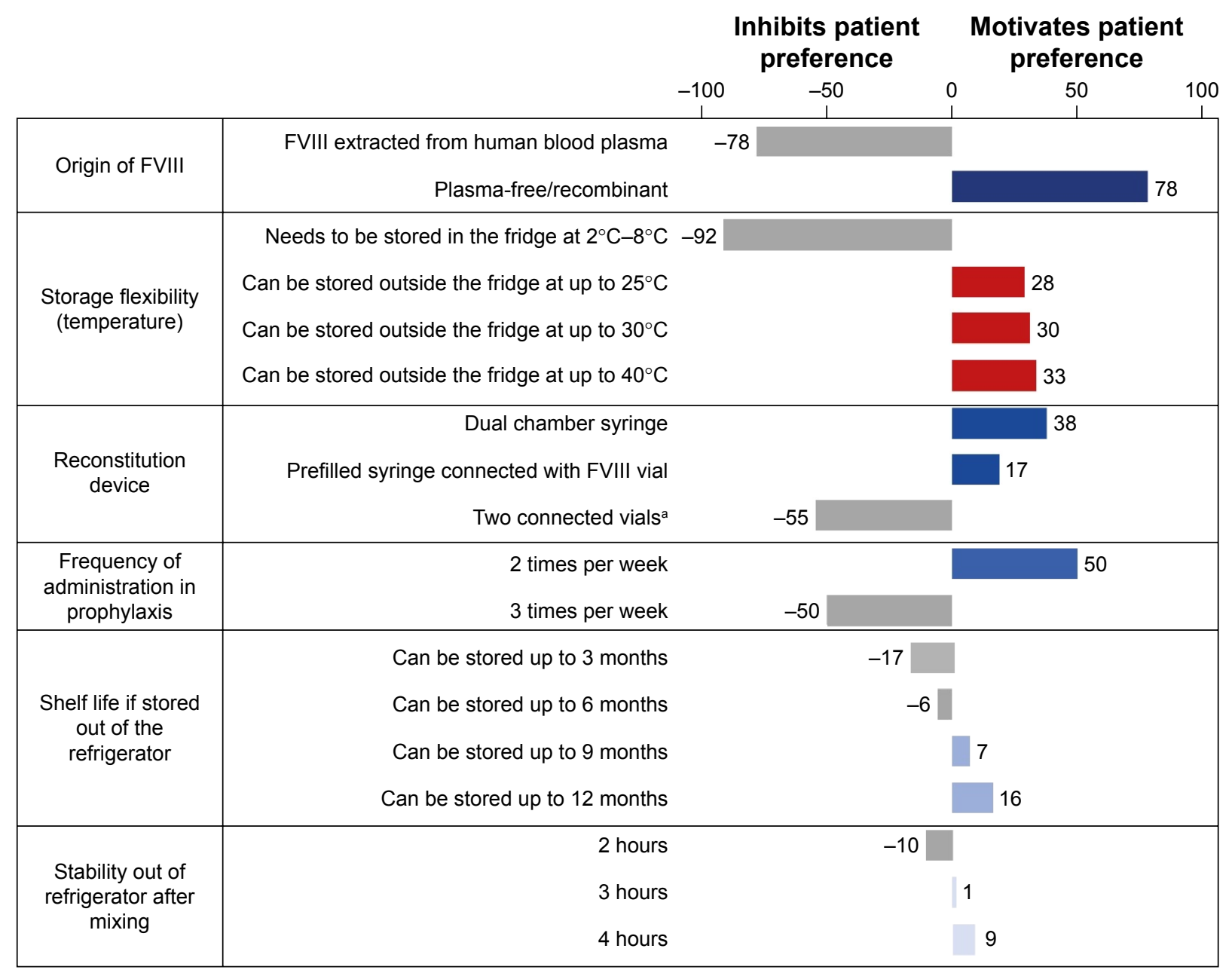

Figure 2 Effect of attribute levels on product choice: part-worth utilities.

Notes: aix FVIII with 2 connected vials. One vial contains FVIII powder, and the other contains solvent. Then put the mixed factor into a syringe connected with the vials. Abbreviation: FVIII, factor VIII.

traveled more frequently; spent less time to prepare and mix FVIII; and found storage, preparation, and mixing their FVIII to be less disruptive.

However, these observed associations may not be truly linked to causality. For example, frequent traveling could be the reason for storing FVIII product at room temperature. The same applies to other associations observed in this study such as that of a high restriction of sports activities in the group of patients who stored FVIII in their refrigerator. These associations could have been caused by other "hidden" variables, such as age, education, socioeconomic status, or anxiety levels regarding the use of FVIII. Indeed, "relaxed" was the only emotional attribute distinguishing both patient groups.

Interestingly, region/country of origin and travel frequency were the only demographic variables to show a significant difference between patients who stored the product inside or outside the refrigerator. In Latin America, none of the patients in the sample stored their FVIII product outside the refrigerator, which may have been related to climatic factors. It is also possible that Latin American patients had a lower socioeconomic status that is reflected by a lower travel frequency, suggesting that their satisfaction with travel-related aspects could be a demographic artifact. However, between Latin American patients and patients living in Europe/Japan, the travel frequency did not differ significantly regarding average number of travels per year (Latin America: 10.3 travels; Europe/Japan: 10.5 travels). Nevertheless, the subgroup of patients $(n=31)$ storing FVIII at room temperature was too small to draw firm conclusions and further studies are required to investigate the impact of storage on patient satisfaction and preference.

Results from the conjoint analysis, in which all 200 patients were asked to select their preferred product attributes, showed that the most powerful driver of product choice was "origin 
of FVIII". Importantly, patients had a preference for recombinant products. Nowadays, recombinant coagulation FVIII products are considered safer than plasma-derived FVIII in terms of transmission of blood-borne pathogens. ${ }^{20,21}$

Interestingly, although most of the patients (85\%) stored their FVIII product in the refrigerator, the second strongest driver of product choice was "storage flexibility (temperature)". This contradiction in findings may be explained by the fact that most patients were unaware that current FVIII products can be stored safely outside the refrigerator.

Genetic engineering of new recombinant products aims to improve some specific therapeutic aspects, such as immunogenicity, neoantigenicity, and stability, and overcome limitations of the manufacturing process. ${ }^{22}$ From a physician's perspective, the clinical use of new drugs should encompass several variables, including, if possible, a convenient product administration. ${ }^{23}$ In the current survey, "frequency of administration in prophylaxis" was much less of a driver of choice than may have been expected from previous studies. ${ }^{13,15}$ Nevertheless, the overall results from this study support the premise that patients prefer to have fewer injections without compromising efficacy.

\section{Conclusion}

This study provides clear evidence that most of the patients with hemophilia A were unaware that currently available FVIII products can be stored safely outside the refrigerator. If the result is representative of the worldwide hemophilia A population, then it is reasonable to conclude that current storage practices are not aligned with those of modern FVIII products, which can be stored safely outside the refrigerator, but at specified temperatures and with limited shelf life. When patients were informed of this possibility, storage of FVIII products outside the refrigerator was found to be the second highest driver of product choice if product efficacy, safety, and administration frequency were maintained.

From a physician's perspective, adherence to treatment is essential for an accurate clinical evaluation of breakthrough bleeding during prophylaxis. ${ }^{24-26}$ Therefore, behavioral techniques need to be implemented, with better communication from health care providers to explain product storage. ${ }^{27}$

\section{Acknowledgments}

This survey was supported by Novo Nordisk Pharma AG, Zürich, Switzerland.

\section{Author contributions}

Bernd Tischer performed this research and wrote the paper. Renato Marino and Mariasanta Napolitano contributed essential parts of the manuscript. All authors contributed toward data analysis, drafting and revising the paper and agree to be accountable for all aspects of the work.

\section{Disclosure}

The authors report no conflicts of interest in this work.

\section{References}

1. Bolton-Maggs PH, Pasi KJ. Haemophilias A and B. Lancet. 2003; 361(9371):1801-1809.

2. Manco-Johnson MJ, Abshire TC, Shapiro AD, et al. Prophylaxis versus episodic treatment to prevent joint disease in boys with severe hemophilia. N Engl J Med. 2007;357(6):535-544.

3. Krishnan S, Vietri J, Furlan R, Duncan N. Adherence to prophylaxis is associated with better outcomes in moderate and severe haemophilia: results of a patient survey. Haemophilia. 2015;21(1):64-70.

4. Srivastava A, Brewer AK, Mauser-Bunschoten EP, et al; Treatment Guidelines Working Group on Behalf of The World Federation Of Hemophilia. Guidelines for the management of hemophilia. Haemophilia. 2013;19(1):e1-e47.

5. Berntorp E, Dolan G, Hay C, et al. European retrospective study of real-life haemophilia treatment. Haemophilia. 2017;23(1):105-114.

6. Morfini M, Benson G, Jiménez-Yuste V, et al. Tailoring care to haemophilia patients' needs: which specialty and when? Blood Transfus. 2015; 13(4):644-650.

7. Oladapo AO, Epstein JD, Williams E, Ito D, Gringeri A, Valentino LA. Health-related quality of life assessment in haemophilia patients on prophylaxis therapy: a systematic review of results from prospective clinical trials. Haemophilia. 2015;21(5):e344-e358.

8. Cimino E, Linari S, Malerba M, Halimeh S, Biondo F, Westfeld M. Patient preference and ease of use for different coagulation factor VIII reconstitution device scenarios: a cross-sectional survey in five European countries. Patient Prefer Adherence. 2014;8:1713-1720.

9. Saxena K. Barriers and perceived limitations to early treatment of hemophilia. J Blood Med. 2013;4:49-56.

10. Ringwald J, Rudolph P, Biner M, et al. Travel behaviour of patients with haemophilia. Travel Med Infect Dis. 2013;11(3):159-165.

11. DiBenedetti DB, Coles TM, Sharma T, Pericleous L, Kulkarni R. Assessing patients' and caregivers' perspectives on stability of factor VIII products for haemophilia A: a web-based study in the United States and Canada. Haemophilia. 2014;20(4):e296-e303.

12. Kappelgaard AM, Metzinger CP, Schnabel D. A web-based survey assessing the impact of storage flexibility on the daily life of patients and caregivers administering growth hormone. Expert Rev Med Devices. 2015;12(5):517-527.

13. Chaugule SS, Hay JW, Young G. Understanding patient preferences and willingness to pay for hemophilia therapies. Patient Prefer Adherence. 2015;9:1623-1630.

14. Fernández-Arias I, Kim HK. Factor VIII delivery devices in haemophilia A. Barriers and drivers for treatment adherence. Farm Hosp. 2016;40(n06):579-603.

15. Furlan R, Krishnan S, Vietri J. Patient and parent preferences for characteristics of prophylactic treatment in hemophilia. Patient Prefer Adherence. 2015;9:1687-1694.

16. Mahlangu J, Powell JS, Ragni MV, et al; A-LONG Investigators. Phase 3 study of recombinant factor VIII Fc fusion protein in severe hemophilia A. Blood. 2014;123(3):317-325.

17. Collins PW. Personalized prophylaxis. Haemophilia. 2012;18 (Suppl 4): 131-135.

18. Dunn A. The long and short of it: using the new factor products. Hematology Am Soc Hematol Educ Program. 2015;2015:26-32.

19. Novais T, Duclos A, Varin R, Lopez I, Chamouard V. Treatment-related knowledge and skills of patients with haemophilia and their informal caregivers. Int J Clin Pharm. 2016;38(1):61-69.

20. Farrugia A. Safety issues of plasma-derived products for treatment of inherited bleeding disorders. Semin Thromb Hemost. 2016;42(5):583-588. 
21. Franchini M, Coppola A, Rocino A, et al. Perceived challenges and attitudes to regimen and product selection from Italian haemophilia treaters: the 2013 AICE survey. Haemophilia. 2014;20(2): e128-e135.

22. Kamionka M. Engineering of therapeutic proteins production in Escherichia coli. Curr Pharm Biotechnol. 2011;12(2):268-274.

23. Santagostino E, Auerswald G, Benson G, et al. Switching treatments in haemophilia: is there a risk of inhibitor development? Eur J Haematol. 2015;94(4):284-289.

24. Armstrong EP, Malone DC, Krishnan S, Wessler MJ. Adherence to clotting factors among persons with hemophilia A or B. Hematology. 2015;20(3):148-153.
25. Thornburg CD. Physicians' perceptions of adherence to prophylactic clotting factor infusions. Haemophilia. 2008;14(1):25-29.

26. Witkop ML, McLaughlin JM, Anderson TL, Munn JE, Lambing A, Tortella B. Predictors of non-adherence to prescribed prophylactic clotting-factor treatment regimens among adolescent and young adults with a bleeding disorder. Haemophilia. 2016;22(4):e245-e250.

27. Ljung R, Auerswald G, Benson G, et al. Novel coagulation factor concentrates: issues relating to their clinical implementation and pharmacokinetic assessment for optimal prophylaxis in haemophilia patients. Haemophilia. 2013;19(4):481-486.

\section{Publish your work in this journal}

Patient Preference and Adherence is an international, peer-reviewed, open access journal that focuses on the growing importance of patient preference and adherence throughout the therapeutic continuum. Patient satisfaction, acceptability, quality of life, compliance, persistence and their role in developing new therapeutic modalities and compounds to optimize clinical outcomes for existing disease states are major areas of interest for the journal. This journal has been accepted for indexing on PubMed Central. The manuscript management system is completely online and includes a very quick and fair peer-review system, which is all easy to use. Visit http://www. dovepress.com/testimonials.php to read real quotes from published authors.

Submit your manuscript here: http://www.dovepress.com/patient-preference-and-adherence-journal 